\title{
CLINICAL STUDY OF CLEFT LIP AND PALATE AND RARE FACIAL CLEFTS IN UPPER ASSAM AND ARUNACHAL PRADESH
}

\author{
Utpal K. R. Bordoloi ${ }^{1}$
}

${ }_{1}^{1}$ Associate Professor, Department of Plastic Surgery, Assam Medical College, Dibrugarh, Assam, India.

\section{ABSTRACT}

\section{BACKGROUND}

Facial clefts occur in varying degree of severity and variety of patterns. It is a nightmare which every parent wants to avoid. Facial clefts occur when the structures contributing to the formation of face namely- the frontonasal prominence, the maxillary prominence, the medial nasal prominence, the lateral nasal prominence and the mandibular prominences fail to fuse with one another. Many rare facial clefts cannot be explained by simple embryological concepts. These defects result in abnormal facial appearance, difficulties in feeding, defective teeth, defective speech, repeated infections and social stigma.

The study was carried out from January 2008 to June 2018, among the 1000 cases of facial clefts who attended the Smile Train Centre in Srishti Hospitals and Plastic SOPD of Assam Medical College Hospital, Dibrugarh, Assam.

\section{MATERIALS AND METHODS}

This descriptive study was carried out among the 1000 cases of facial clefts who attended the Smile Train Centre at Srishti Hospitals and PSOPD in AMCH, Dibrugarh, Assam, from January 2008 to June 2018. All the cases were evaluated on the basis of sex, religion, race, type of cleft, severity of the cleft, family history of facial clefts, birth order, consanguinity, maternal age, associated disease, radiation exposure and drug history during $1^{\text {st }}$ trimester of pregnancy. Also, the socio-economic status, parents' literacy, source of information for treatment and parents' satisfaction after treatment was noted down.

\section{RESULTS}

It was found that isolated cleft lip (42.2\%) occurred more commonly than isolated cleft palate (15.1\%). Cleft lip was more common in males (55.7\%) than in females (44.3\%). 412 (41.2\%) of the cases presented with both cleft lip and palate and among these 268 $(65.04 \%)$ were females and 144 (34.95\%) were males. Isolated cleft palate was found to be more common in females (71.5\%) than in males (28.09\%). All these cases underwent reconstructive surgery and left the hospital with a sociably presentable face.

\section{CONCLUSION}

Cleft lip and palate and rear facial clefts are no longer considered a stigma, as they are surgically correctable.

\section{KEY WORDS}

Cleft Lip, Cleft Palate, Rare Facial Cleft, Tessier's Cleft, Transverse Facial Cleft.

HOW TO CITE THIS ARTICLE: Bordoloi UKR. Clinical study of cleft lip and palate and rare facial clefts in upper Assam and Arunachal Pradesh. J. Evolution Med. Dent. Sci. 2018;7(40):4326-4330, DOI: 10.14260/jemds/2018/965

\section{BACKGROUND}

The face in a human embryo is formed by fusion of some facial prominences that appear in the $4^{\text {th }}$ week of development. The frontonasal prominence forms the forehead, bridge of the nose, medial and lateral nasal prominences. The maxillary prominence forms the cheeks and lateral portion of upper lip. The medial nasal prominence forms the philtrum of upper lip, crest and tip of nose, while the lateral nasal prominence forms the ala of nose. The mandibular prominence forms the entire lower lip and jaw. Different types of cleft lip result if the medial nasal prominence fail to fuse with the maxillary prominences. Bilateral cleft lip occurs due to failure of both maxillary processes to fuse with the medial nasal prominence, which then appears as a separate flap. Failure of whole maxillary prominence to fuse with the lateral margin of the lateral nasal

'Financial or Other Competing Interest': None.

Submission 21-08-2018, Peer Review 15-09-2018,

Acceptance 21-09-2018, Published 01-10-2018.

Corresponding Author:

Dr. Utpal K. R. Bordoloi,

Department of Plastic Surgery,

AMCH, Dibrugarh-786002,

Assam, India.

E-mail: utpalbordoloi50@gmail.com

DOI: $10.14260 /$ jemds/2018/965

\section{(c) (1) $(9)$}

prominence results in an oblique facial cleft. Cleft palate results due to failure of fusion of the palatine shelves with each other or with the anterior triangular primary palate. Cleft lip and cleft palate are one of the most common congenital deformities. The incidence of cleft lip is approximately $1 / 1000$ births and it occurs more frequently in males $(80 \%)$ than in females. The incidence of cleft palate is approximately $1 / 2500$ births and occurs more often in females $(67 \%)$ than in males.(1,2) To have a child with grossly deformed face is certainly a horrifying experience for the entire family. For all such children, the problem goes beyond the obvious disfigurement of the face to repeated infections, social stigma, problems with speech, hearing and teeth formation. (3) These children are often teased by their friends and they lose self-confidence. They suffer with emotional "burn out" in adolescence.(4) Children with clefts often suffer from anaemia and malnutrition, mainly due to poverty and illiteracy on the part of the parents. In addition, due to lack of awareness many patients of cleft lip remain untreated or mistreated by quacks.(5) All children born with a cleft lip or palate need thorough paediatric assessment to exclude other congenital abnormalities. Genetic counselling must be sought if a syndrome is suspected. Keeping in mind that no studies regarding the incidence of cleft lip and palate are published from this part of Assam, India. This study was undertaken to form a clinical picture of the patients specific to this region for the benefit of public and the treating doctors. 


\section{MATERIALS AND METHODS}

This descriptive study was carried out among the 1000 cases of facial clefts who attended the Smile Train Centre at Srishti Hospitals and PSOPD in AMCH, Dibrugarh, Assam, from January 2008 to June 2018. All the cases were evaluated on the basis of sex, religion, race, type of cleft, severity of the cleft, family history of facial clefts, birth order, consanguinity, maternal age, associated disease, radiation exposure and drug history during $1^{\text {st }}$ trimester of pregnancy. Also, the socio-economic status, parents' literacy, source of information for treatment and parents' satisfaction after treatment was noted down.

The Aims and Objectives of this Study are-

1. To study the incidence of isolated cleft lip.

2. To study the incidence of isolated cleft palate.

3. To study the incidence of cleft lip with cleft palate.

4. To study the incidence of rare facial clefts.

5. To study the result of surgical correction.

\section{RESULTS}

The data collected were tabulated and analysed as follows-

\begin{tabular}{|c|c|c|}
\hline Male & Female & Total \\
\hline $557(55.7 \%)$ & $443(44.3 \%)$ & 1000 \\
\hline \multicolumn{2}{|c|}{ Table 1. Showing Sex distribution of the Cases } \\
\hline
\end{tabular}

\begin{tabular}{|c|c|c|c|c|}
\hline $\begin{array}{c}\text { Isolated } \\
\text { Cleft Lip }\end{array}$ & $\begin{array}{c}\text { Isolated } \\
\text { Cleft } \\
\text { Palate }\end{array}$ & $\begin{array}{c}\text { Cleft Lip } \\
\text { with Cleft } \\
\text { Palate }\end{array}$ & $\begin{array}{c}\text { Rare Facial } \\
\text { Clefts }\end{array}$ & Total \\
\hline $\begin{array}{c}422 \\
(42.2 \%)\end{array}$ & $151(15 \%)$ & $412(41.2 \%)$ & $15(1.5 \%)$ & 1000 \\
\hline \multicolumn{5}{|c|}{ Table 2. Showing Types of Facial Clefts } \\
\hline
\end{tabular}

\begin{tabular}{|c|c|c|}
\hline Unilateral & Bilateral & Total \\
\hline $373(88.39 \%)$ & $49(11.6 \%)$ & 422 \\
\hline \multicolumn{2}{|c|}{ Table 3. Showing Side distribution of Cleft Lip (CL) } \\
\hline
\end{tabular}

\begin{tabular}{|c|c|c|}
\hline Right Sided & Left Sided & Total \\
\hline $135(36.19 \%)$ & $238(63.80 \%)$ & 373 \\
\hline \multicolumn{2}{|c|}{ Table 4. Showing Side distribution of Unilateral Cleft Lip } \\
\hline
\end{tabular}

\begin{tabular}{|c|c|c|c|c|}
\hline \multicolumn{2}{|c|}{ Right Side } & \multicolumn{2}{c|}{ Left Side } & Total \\
\hline Complete & Incomplete & Complete & Incomplete & \\
\hline 57 & 98 & 85 & 133 & 373 \\
\hline \multicolumn{2}{|c|}{ Table 5. Showing Completeness of Unilateral Cleft Lip } \\
\hline
\end{tabular}

\begin{tabular}{|c|c|c|}
\hline Sex & No. of Cases & Total \\
\hline Male & $276(65.4 \%)$ & 422 \\
\hline Female & $146(34.59 \%)$ & \\
\hline \multicolumn{2}{|c|}{ Table 6. Showing Sex distribution of Cleft Lip } \\
\hline
\end{tabular}

\begin{tabular}{|c|c|c|}
\hline Sex & No. of Cases & Total \\
\hline Male & $144(34.95 \%)$ & 412 \\
\hline Female & $268(65.04 \%)$ & \\
\hline \multicolumn{3}{|c|}{ Table 7. Showing Sex distribution of Cleft Lip with Cleft } \\
Palate \\
\hline
\end{tabular}

\begin{tabular}{|c|c|c|}
\hline Sex & No. of Cases & Total \\
\hline Male & $43(28.09 \%)$ & \multirow{2}{*}{151} \\
\hline Female & $108(71.52 \%)$ & \\
\hline \multicolumn{2}{|c|}{ Table 8. Showing Sex distribution of Isolated Cleft Palate } \\
\hline
\end{tabular}

\begin{tabular}{|c|c|c|}
\hline Complete & Incomplete & Total \\
\hline 412 & 151 & 563 \\
\hline \multicolumn{2}{|c|}{ Table 9. Showing Type of Cleft Palate } \\
\hline
\end{tabular}

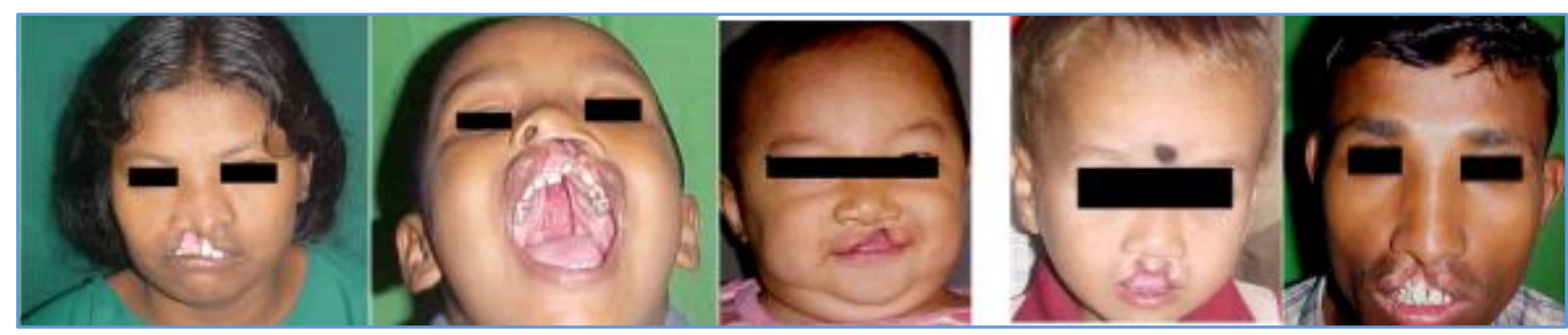

Photograph 1. Few Cases of Complete Cleft Lip and Palate and Incomplete Cleft Lip

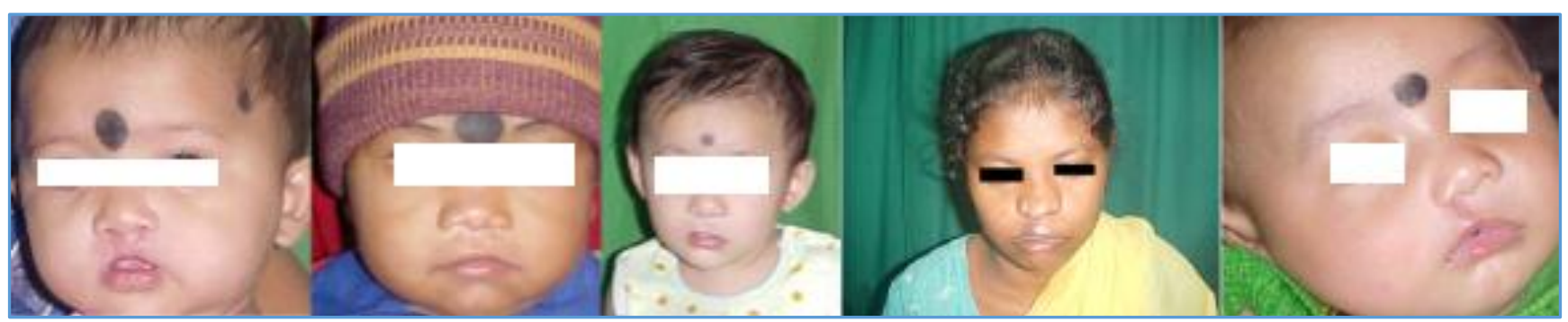

Photograph 2. Few Post-Operative Cases of Cleft Lip

As for family history, in only one family both the parents had cleft lip and palate and now their two siblings have the same deformity. The age of the cases ranged from 3 months to 25 years. The maternal age ranged between 18 - 39 years. 


\begin{tabular}{|c|c|}
\hline Anaemia & $\mathbf{6 1 3}$ \\
\hline Delayed milestone & 22 \\
\hline Mental retardation & 2 \\
\hline Respiratory illness & 102 \\
\hline Ear infection & 13 \\
\hline Underweight for age & 160 \\
\hline Associated congenital anomaly & Table 10. Showing associated IIIness \\
\hline
\end{tabular}

\begin{tabular}{|c|c|c|}
\hline Hb (gm\%) & Number of Cases & Percentage \\
\hline $7-8$ & 36 & $3.6 \%$ \\
\hline $8.1-9$ & 232 & $23.2 \%$ \\
\hline $9.1-10$ & 210 & $21 \%$ \\
\hline $10.1-11$ & 135 & $13.5 \%$ \\
\hline $11.1-12$ & 297 & $29.7 \%$ \\
\hline $12.1-13$ & 90 & $9 \%$ \\
\hline \multicolumn{2}{|c|}{ Table 11. Haemoglobin Level of the Patients } \\
\hline
\end{tabular}

It was found that majority of the cases were suffering from anaemia. Approximately, $38 \%$ of the cases had haemoglobin level ranging between 11 to $13 \mathrm{gm} \%$.

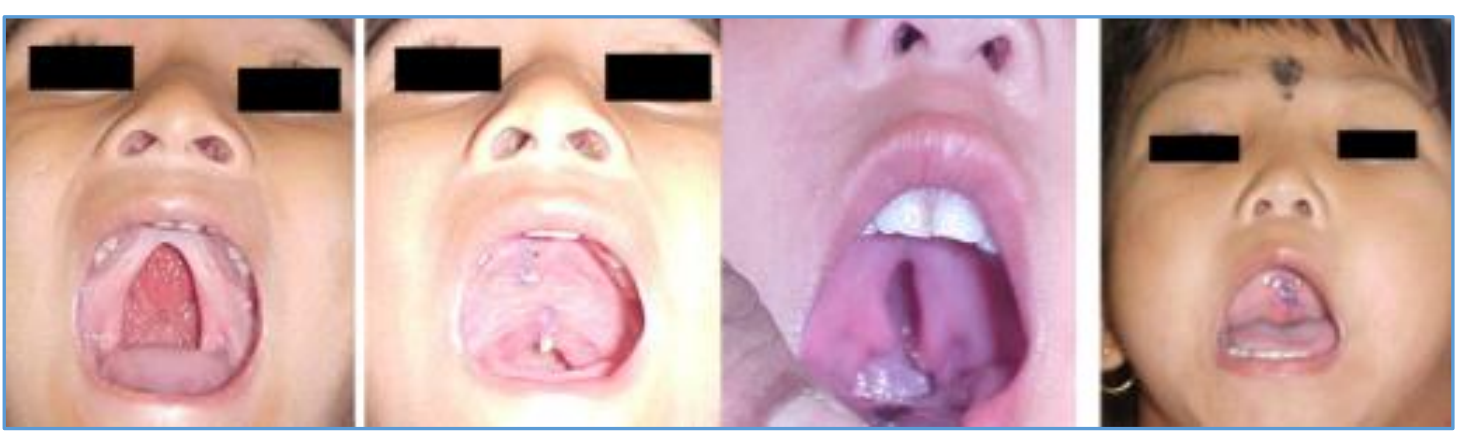

Photograph 3. Two Cases of Cleft Palate, Pre-and Post-Operative

\begin{tabular}{|c|c|}
\hline Type & Number of Cases \\
\hline Tessier cleft 3, bilateral & 1 \\
\hline Tessier cleft 3 and 4 & 1 \\
\hline Tessier cleft 4 & 2 \\
\hline Tessier cleft 7 & 11 \\
\hline \multicolumn{2}{|c|}{ Table 12. Rare Facial Clefts } \\
\hline
\end{tabular}

Thus, from the data summarised in Tables 1 - 11, it is seen that majority of the cleft patients were males. Most of the families said that they came to know about the treatment facilities from friends and also from advertisements on radio and television. Since majority of them were of lower socioeconomic status, they were grateful that such free treatment was available at their doorstep. The study also shows that $0.64 \%$ of parents of children with facial clefts were absolutely illiterate, $37.77 \%$ of parents were undergraduates and $61.58 \%$ of parents were graduates. As for maternal antenatal history, $15 \%$ of women never took iron and folic acid during pregnancy, $41 \%$ of women took the same but irregularly and the rest $44 \%$ of women regularly supplemented their nutritional requirements as per advice of their doctors. The age of the mother ranged from 18 to 37 years in this study and 52 were consanguineous marriages.

\begin{tabular}{|c|c|c|}
\hline Race or Tribe & No. of Cases & \% \\
\hline Tea-garden community & 244 & $24.4 \%$ \\
\hline Assamese (General) & 155 & $15.5 \%$ \\
\hline Ahom & 230 & $23 \%$ \\
\hline Mishing & 89 & $8.9 \%$ \\
\hline Kachari & 59 & $5.9 \%$ \\
\hline Bengali & 48 & $4.8 \%$ \\
\hline Bihari & 29 & $2.9 \%$ \\
\hline Nepali & 31 & $3.1 \%$ \\
\hline Arunachali & 47 & $4.7 \%$ \\
\hline Naga & 32 & $3.2 \%$ \\
\hline Others & 36 & $3.6 \%$ \\
\hline Table 13. Showing Ethnic distribution of Cleft Lip and \\
Palate \\
\hline \multicolumn{2}{|c|}{}
\end{tabular}

As can be seen, facial clefts are more common among the Ahom community (21.89\%) and the Tea-garden community (21.28\%) of Assam as compared to others.

\begin{tabular}{|c|c|}
\hline Type of Operation & Number of Cases \\
\hline Rotation and Advancement & 316 \\
\hline Triangular variant & 439 \\
\hline Straight line repair and others & 79 \\
\hline \multicolumn{2}{|c|}{ Table 14. Type of Surgery done for Cleft Lip } \\
\hline
\end{tabular}

\begin{tabular}{|c|c|}
\hline Type of Operation & Number of Cases \\
\hline Veau repair & 5 \\
\hline $\begin{array}{c}\text { Straight line double stage } \\
\text { repair }\end{array}$ & 42 \\
\hline Others & 2 \\
\hline \multicolumn{2}{|c|}{ Table 15. Type of Surgery for Bilateral Cleft Lip } \\
\hline
\end{tabular}

\begin{tabular}{|c|c|}
\hline Type of Operation & Number of Cases \\
\hline Veau-Kilner-Wardill & 72 \\
\hline Furlow's procedure & 12 \\
\hline Delaire two-stage procedure & 36 \\
\hline Langenbeck procedure & 159 \\
\hline Push back procedure & 284 \\
\hline \multicolumn{2}{|c|}{ Table 16. Surgery done for Cleft Palate Cases } \\
\hline
\end{tabular}

\begin{tabular}{|c|c|}
\hline Complications & Number of Cases \\
\hline Wound dehiscence & 6 \\
\hline Bleeding & 2 \\
\hline Scar hypertrophy & 40 \\
\hline Cupids bow defect & 10 \\
\hline Residual nasal deformity & 228 \\
\hline \multicolumn{2}{|c|}{ Table 17. Complications of Cleft Lip Surgery } \\
\hline
\end{tabular}

\begin{tabular}{|c|c|}
\hline Complications & Number of Cases \\
\hline Bleeding & 4 \\
\hline Dehiscence & 12 \\
\hline Fistula & 20 \\
\hline Table 18. Complications of Cleft Palate Surgery \\
\hline
\end{tabular}


Operations for wound dehiscence, fistula and residual nasal deformity are not included in the present study.

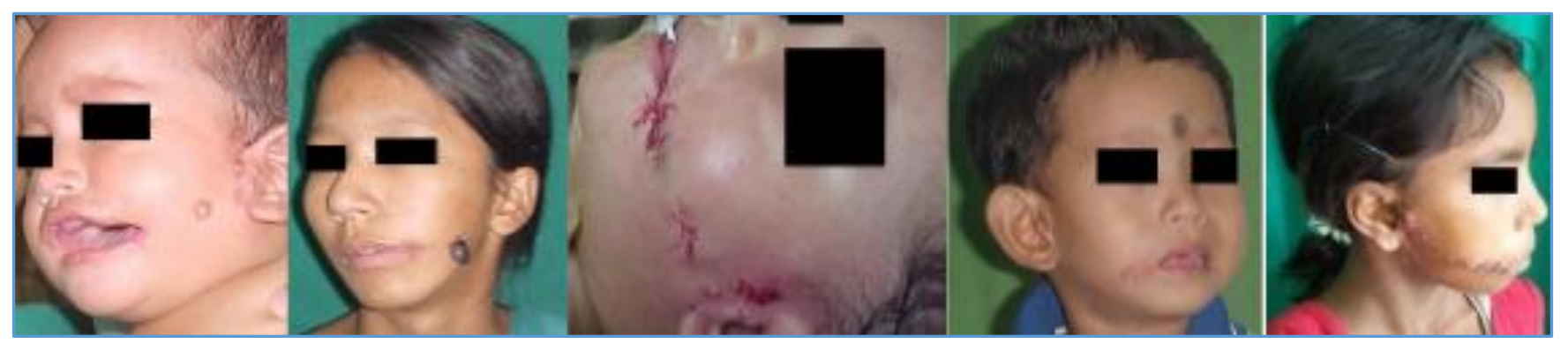

Photograph 4. Few Cases of Rare Facial Clefts; Pre- and Immediate Post-Operative

\section{DISCUSSION}

Due to illiteracy facial clefts are still presumed to be a curse of God by various sections of the society, especially in remote areas. Review of studies shows that there are no trends for incidence of cleft lip and palate in different parts of the world. According to a WHO study on craniofacial anomalies carried out in 13 countries, the incidence varies from 0.22 to 1.67 per thousand live births.(6)

According to available literature, the incidence of cleft lip and palate exhibit ethnic variation. It is found to be highest in Asian or Native North American descents followed by the Caucasians. It is least among the Africans.(7) In the present study, we found it to be more common in Ahom community and the Tea-garden community of Assam.

Fogh-Anderson(8) reported that siblings of patients with cleft lip and palate have an increased incidence of cleft lip and palate, but not isolated cleft palate; conversely, siblings of patients with cleft palate have an increased frequency of cleft palate but not of cleft lip and palate. He also found that 30$40 \%$ of 703 patients with cleft lip or cleft palate in Denmark had near relative with similar deformities. But in the present study, only $0.12 \%$ of 781 cases had near relative with similar deformity.

As for sex ratio, there is an excess of cleft lip and palate in males. Female excess has been reported in isolated cleft palate. $(8,9,10)$ The findings of our study is also similar. Cleft lip occurred more in males $(65.4 \%)$ than in females $(34.59 \%)$. Cleft palate occurred in a higher frequency in females (71.52\%) than in males $(28.09 \%)$.

As noted by Fogh-Anderson( ${ }^{8)}$ and confirmed by many other studies, $(9,10,11,12,13)$ there is a left-sided preponderance of cleft lip. In this study also, cleft lip was more (63.80\%) on the left side and less (36.19\%) on the right side.

Patients of facial clefts are brought for surgery later than the ideal surgical time which may be due to ignorance, poverty or unawareness about the fact that such anomaly can be corrected by surgery. Without repair these children would have suffered from social isolation, feeding problem, abnormal speech and repeated infections.(14) Many patients do not come to the hospital, because they cannot afford the treatment offered. May be this is the reason why the maximum age was 25 years in our study.

As stated earlier, we also enquired about the type of marriage and found that consanguineous marriage is not an uncommon practice in the state.

To correct the facial clefts, different standard operative procedures were followed.(15,16,17,18,19,20,21) Majority of cleft palate cases (284) were corrected by pushback procedure followed by Langenbeck procedure (159 cases). Among the bilateral cleft lip cases, 42 were corrected by Veau III and two stage repair procedures. Few complications in some cases were corrected subsequently.

\section{CONCLUSION}

Cleft lip and palate is no longer considered a stigma, as these deformities can be corrected by various surgical procedures. Most of these operations take about 45 minutes to one and a half hours' time. It is found that cleft lip and palate is more common in males and on the left side. However, isolated cleft palate is more common in females. Transverse facial cleft is the most common rare facial cleft in our study. Anaemia is the most commonly associated condition followed by underweight for age and respiratory illness. Similarly, maternal malnutrition and anaemia is commonly seen. Most of the cases belonged to lower socio-economic group. Out of 1000 cases, highest number of cases are from Tea-garden community (244) followed by Ahom community (230). Various operative procedures were performed for cleft lip and palate. All cases were done under general anaesthesia. Cleft lip and cleft palate operations were done in separate stages. Rotation and advancement and triangular flap procedures were most commonly done procedures for cleft lip, whereas pushback procedure and Langenbeck procedures were most commonly done for cleft palate. Two stage repair procedure was commonly done for bilateral cleft lip. Commonly encountered complications for cleft lip included scar hypertrophy and residual nasal deformity and for cleft palate; palatal fistula.

\section{REFERENCES}

[1] Sadler TW. Langman's medical embryology. $11^{\text {th }}$ edn. Lippincott Williams and Wilkins 2011: p. 280-7.

[2] Hamilton WJ, Boyd JD, Mossman HW. Hamilton, Boyd and Mossman's human embryology: prenatal development of form and function. $4^{\text {th }}$ edn. London: The Macmillan Press Ltd., 1978: p. 293-302.

[3] Dvivedi J, Dvivedi S. A clinical and demographic profile of cleft lip and palate in Sub-Himalayan India: a hospital-based study. IJPS 2012;45(1):115-20.

[4] Sridhar K. A community-based survey of visible congenital anomalies in rural Tamil Nadu. Indian Journal of Plastic Surg 2009;42(Suppl):S184-S91. 
[5] Vasan N. Management of children with clefts of the lip or palate: an over view. N Z Dent J 1999;95(419):1420.

[6] Global strategies to reduce the healthcare burden of craniofacial anomalies. Report of WHO meetings on international collaborative research on craniofacial anomalies. Geneva, Switzerland, 2000.

[7] Gorlin RJ, Cohen MM, Hennekem RC. Monographs on medical genetics syndromes of the head and neck. Minneapolis, USA: Oxford University Press 2001.

[8] Fogh-Anderson P. Inheritance of harelip and cleft palate. Copenhagen: Arnold Busck 1942.

[9] Fraser CR, Calnan JS. Cleft lip and palate: seasonal incidence, birth weight, birth rank, sex, site, associated malformations and parental age. A statistical survey. Arch Dis Child 1961;36:420-3.

[10] Blanco-Davila F. Incidence of cleft lip and palate in the Northeast of Mexico: a 10-year study. J Craniofacial Surg 2003;14(4):533-7.

[11] Ingalls TH, Taube IE, Klingberg MA. Cleft lip and cleft palate: epidemiologic considerations. Plast Reconstr Surg 1964;34:1-10.

[12] Fraser FC. The genetics of cleft lip and cleft palate. Am J Hum Genet 1970;22(3):336-52.
[13] Wilson ME. A ten-year survey of cleft lip and cleft palate in South West region. Br J Plast Surg 1972;25(3):224-8.

[14] Gupta K, Bansal P, Dev N, et al. Smile train project: a blessing for population of lower socioeconomic status. J Indian Medical Assoc 2010;108(11):723-5.

[15] Reddy SG, Reddy RR, Bronkhorst EM, et al. Incidence of cleft lip and palate in the state of Andhra Pradesh, south India. Indian J of Plastic Surg 2010;43(2):184-9.

[16] Brown JB, McDowell F. Small triangular flap operation for primary repair of single cleft lips. Plast Reconst Surg 1950;5(5):392-402.

[17] Back C, Jesser J. Plastic surgery of face. Int J Orthod Oral Surg 1921;7:81.

[18] Braurer RO, Cronin TD. Maxillary orthopaedics and anterior palate repair with bone grafting. Cleft Palate J 1964;16:31-42.

[19] Cronin TD. Method of preventing raw area on nasal surface of soft palate in push back surgery. Plast Reconstr Surg (1946) 1957;20(6):474-84.

[20] Devise D. The repair of the unilateral cleft lip. Br J Plast Reconstr Surg 1968;18:254.

[21] Dorrence GM, Brensfield JW. The push back operation for repair of cleft palate. Plast Reconstr Surg 1946;1:145-69. 